\title{
Promoting Speaker Autonomy and Language Confidence through Blooms Taxonomy Based Lessons
}

\author{
M.T.N. Wijetunge* \\ General Sir John Kotelawala Defence University, Rathmalana, Sri Lanka
}

\begin{abstract}
English is a global language at present and it is considered the key to knowledge, information, communication, technology, travel, trade and business and is used as the medium of instruction in most higher education institutes and universities in Asia. Being equipped with the right speaking skills and knowledge in the language boost the chance for employment opportunities in undergraduates. However, majority show reticence towards English 'speaking' even as graduates. There is a great unwillingness to engage in public speaking in English and communication outside the classroom. With this as the main research problem, the aim of this research is to find out effective Communicative Task-Based Activities (CTBA) which can be used in each sphere in the Blooms Taxonomy, to improve speaking confidence in undergraduates. A mixed approach was incorporated in the study. 32 Sri-Lankan undergraduates in the first year were selected as the sample based on purposive sampling and were monitored and taught for a period of one academic semester (15 weeks) based on CTBA. According to Blooms Taxonomy (1956), initial activities were designed for small groups and later the group numbers were gradually reduced to promote autonomous/ independent speaking skills in students. The CTBA was divided into pre, during and post-task phases. SPSS was utilized to quantitatively analyze the data. Thematic content analysis was followed to analyze the interviews. In conclusion, it was revealed that speaker autonomy can be achieved with the correct use of Blooms Taxonomy by incorporating CTBAs correctly at each level in the 6 spheres.
\end{abstract}

Keywords: CTBA, Confidence, Blooms Taxonomy, Autonomy

\section{Introduction}

English is a global language at present and it is considered as the key to knowledge, information, communication, technology, travel, trade and business (Turmapang, 2012). As there is a continuous rise in the unity of people in the globe, one common language has become a necessity as a communication tool. Thus, English language plays a major role in creating global access. English is the official native language in more than 50 countries and is spoken by approximately 1.5 billion people around the world and it has been revealed that less than 400 million people use it as a first language (Eastbourne, 2017, p.1).

As a result, people have begun to use English as a common language in Asia. India claims to be the largest English speaking country in the world at present. "Asia has around 800 million English speakers, and is widespread in Asia mainly because of the two important powers; China and India" (Herscovitch, 2012, p. 1). Across Asia, the numbers of people having "at least a functional command of the language have grown exceptionally over the last four decades" (Bolten, 2008, p.2). Due to the rapid sociolinguistic realities of the region, one must be able to communicate in a global language which is understood by many in order to get along in society. For social recognition, acceptance and even for every day general communication purposes, knowing a common language such as English has become a primary need in Asia.

Realizing this, the Sri Lankan governments introduced English to the local school curriculum not recently, but a few decades back. "Since the early 1950s, the successive governments in Sri Lanka made it a point to teach English to all public schools in the country" (Perera, 2008, p.7). The local school children begin learning English at Grade 3 and complete two competitive examinations; General Certificate in Education in Ordinary Level (G.C.E. (O/L)) and General Certificate in Education in Advanced Level (G.C.E. (A/L)) prior to entering 
university as undergraduates. According to Gnanaseelan (2001) "Both the mother tongue and English could be used as mediums at state universities in Sri Lanka" (p.6). Also, English language has been declared as the link language of the country by the constitutional provision in 1978 (Attanayake, 2018).

Even though the subjects are taught either in the mother tongue or in English medium at the university level, it is expected that the students follow the subject content in English medium as English language becomes the language of communication and will be immensely beneficial once they graduate and enter the job market in the future. The job market at present is highly competitive and "Evidence suggests that the labor market has struggled to accommodate this influx of new workers where unemployment rates hover at a staggering 30 percent" (Baalasuriya \& Hughes, 2003, p.2). This is the main reason why a graduate must be equipped with the right amount of competence, aptitude, self-confidence, extracurricular activities, knowledge in IT and communication skills in English to attract employers. A graduate must be skillful not only in doing a job but also in acquiring one. Therefore, performing confidently and showing motivation at an interview is also a mandatory fact as the interviews are conducted in English medium. Most responsible jobs with considerable salaries are performed in English today in Sri Lanka and therefore, having the right confidence, attitudes and skills is of huge importance.

\section{Research Problem}

Even though Sri Lankan students learn English for a duration of 10 years, starting from Grade 3 to Grade 13, the results it produces at undergraduate level is unsatisfactory. Even though students must excel primarily in their G.C.E. (O/L) and subsequently in G.C.E. (A/L) English examinations to hold a position at a local university, many students lack the ability to communicate in English language by the time they enter the university as undergraduates. This leads to insufficient motivation and lack of confidence to learn and perform in English inside and outside the classroom, making the students become anxiety driven and taciturn as English language users. This results in higher levels of fear and incompetence in English speaking, leading to xenoglossophobia ${ }^{1}$ as it hinders undergraduates' communication competence and performance in the language.

\section{Research Question}

Why are undergraduates reticent to communicate in English and possess less confidence and motivation towards English language?

\section{Aim}

To develop speaker autonomy and confidence via effective Communicative Task-Based Activities (CTBA) which are used in each sphere of the Blooms Taxonomy, to improve speaking confidence in undergraduates

\section{Objectives}

- Improve speaking confidence in undergraduates

- Improve motivation to engage in CTBA

$\circ$ Reduce English speaking anxiety and reticence

- Improve public speaking skills, leadership skills and team-work

\footnotetext{
${ }^{1}$ Fear or using a second or foreign language
} 


\section{Hypothesis}

Gradual implementation of lesson plans (CTBA) set according to the knowledge based-goals of the Blooms Taxonomy, enhances speaking confidence in undergraduates while improving speaker autonomy

\section{Review of Literature}

The review of literature in the research mainly consists of two elements.

\section{Blooms Taxonomy}

Benjamin Bloom with the collaboration of Max Englehart, Edward Furst, Walter Hill, and David published a framework in 1956 for categorizing educational goals which was named as "Taxonomy of Educational Objectives'. The Taxonomy is an "educational-logical-psychological classification system" which is set according to educational principles. Blooms Taxonomy of Educational Objectives is considered as one of the most widely used ways of organizing levels of expertise with regard to education. It has been observed that teachers, administrators, professional specialists and research workers who deal with curricular and evaluation problems may find the taxonomy to be immensely helpful. The problems faced by educators when planning lessons and in choosing learning situations are expected to be reduced as the taxonomy focuses on the "objectives and the behaviors" of the learners. Based on this concept of assisting a learner to gradually reach autonomous skills and abilities and to assist independent functioning, Bloom categorized the Taxonomy of educational objectives mainly into three domains.

1. Knowledge-based goals: These objectives deal with "recall or recognition of knowledge and the development of intellectual abilities and skills" (Bloom, 1956, p.7).

2. Skill-based goals: "Psychomotor objectives are those specific to discreet physical functions, reflex actions and interpretive movements" (Wilson, 2016, p.11).

3. Affective goals (values, attitudes and interests): According to Bloom et al (1956) affective domain has been described as "objectives which makes a change in interest, attitudes, values and the development of appreciation and adequate adjustment" (p.7).

The main focus of the current research is based on the knowledge-based educational goals of the Blooms Taxonomy. The taxonomy is set according to a pyramid containing 6 tiers. These objectives deal with "recall or recognition of knowledge and the development of intellectual abilities and skills" (Bloom (1956, p.7). This is the domain which is the most important from the 3 domains introduced by Bloom (1956) as the framework consists of 6 major categories: Knowledge, Comprehension, Application, Analysis, Synthesis, and Evaluation which improves the cognition of a learner. The 6 levels are fitted to a pyramid where the learners begin at the lowest level 'remembering' and moves up to the highest level 'creating' by achieving each level which assists them to master, develop and acquire each skill. Each category contains subcategories, all lying along a continuum from simple to complex and concrete to abstract (Armstrong, 2019). 


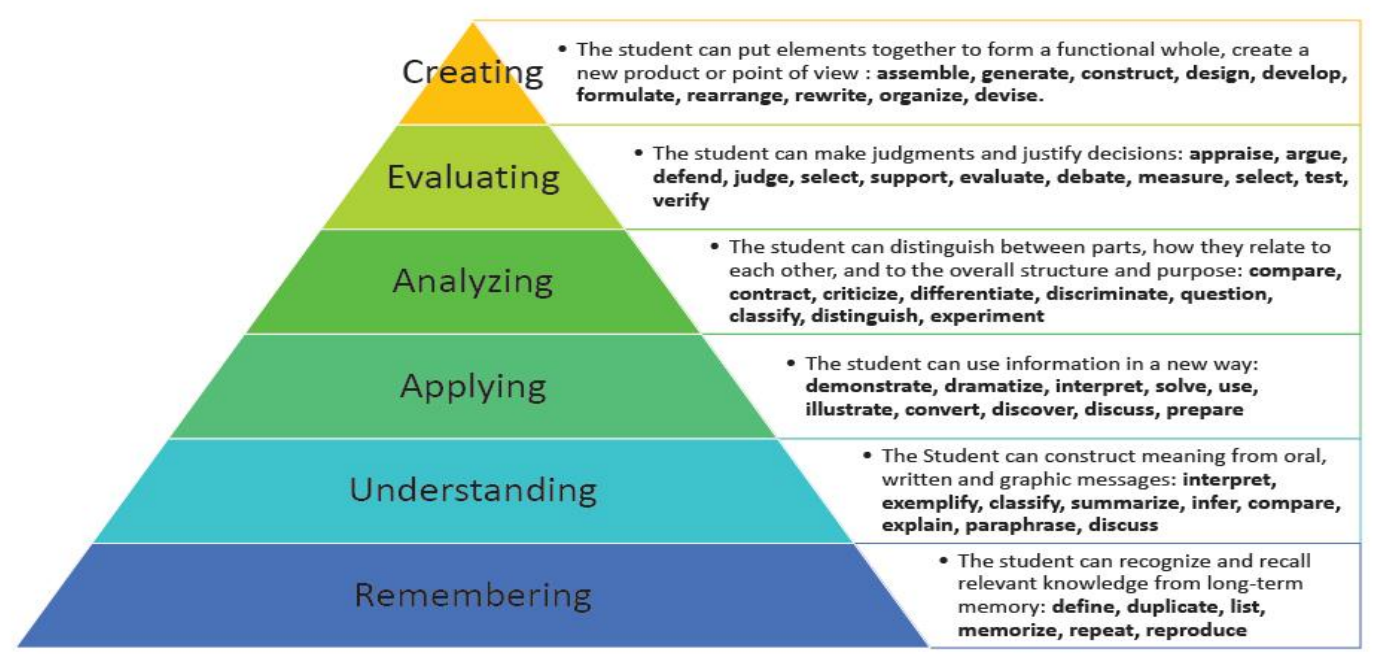

Figure 1:The Blooms Taxonomy

At the completion of each level above, a list of achievable actions that a learner accomplishes is presented in the taxonomy. Various researchers have provided more or less verbs for each level. However, the above figure illustrates the mostly used and researched verbs in the Blooms Taxonomy.

The levels assist to improve the cognition of a learner starting from knowledge-based goals and by moving towards skills-based domain. When the students acquire the necessary knowledge in a subject, he/she eventually develops skills related to it. When considering language speaking, the students will be able to perform in the language with the knowledge acquired initially. This will result in changing the values, attitudes, interests and motivation via affective goals at latter stages. With the achievement of affective domain the students eventually develop their confidence and motivation to speak in English.

\section{Communicative Task-Based Activities (CTBA)}

Task Based Approach (TBA) is interpreted in various ways by researchers and it "gained popularity in the field if language teaching in the $20^{\text {th }}$ century" (Sanchez, 2004, p.39). Task-Based Learning (TBL) is not a new concept and it is used when teaching all four skills in English: reading, writing, speaking and listening. "Students are expected to express their own ideas, either orally or in a written mode about the topic of the lesson"(Willis, 1996, p.23). A task is said to be a classroom activity which is objective and interactive. Tasks also involve learners in 'comprehending, manipulating, producing or interpreting in the target language. As Ganta (2015) describes, there is a linguistic as well as a cognitive element to a task. Tasks are based on activities "which aim at meaning-focused language use. Therefore, a task encourages the participants to function as 'language users' rather than "language learners"' (p.2763). Using the communicative processes is a good way to incorporate real world activities. As Ellis (2009) describes "Tasks involve cognitive processes such as selecting, reasoning, classifying, sequencing information, and transforming information from one form of representation to another" (p.7). In this approach, learners concentrate on meaning rather than form; that is, students carry out a group of tasks instead of doing form-based discrete exercises.

When compared to the age-old methods of teaching such as direct method, grammar-translation method etc, TBA is considered as a highly effective way as it is mainly student-centered. The students are given priority and the dominant role of the teacher is taken away. They are made to work collaboratively with peers and engage in student-interaction. One of the most important factors of TBL is that the students are exposed to a whole range of lexical phrases, collocations and patterns as well as language forms. It is a communicative approach where the students spend a lot of time communicating. Since the students are expected to work together and find out 
how a task should be carried out, it requires them to work together to find out a method to reach an effective language output. As Ganta (2015) mentions in contrast to the traditional teaching methods, "TBA focuses on communication and conveying messages. It gives secondary importance to the forms used" (p. 2760).

CTBAs contain three phases.

\section{a) Pre-tasks}

These are the tasks and activities that the teacher and the students engage in prior to the main task. The teacher introduces the lesson and the topic and explains to the students what needs to be done. Sometimes, there is a brainstorming sessions to assist the students to recall the vocabulary which can be incorporated in the lesson. A model is presented to the students to help them realize what is expected. The students can make notes and involve in the preparation process. In this stage it is necessary to motivate the students by explaining the purpose and use of the specific tasks. They should be told what they are required to do and the objectives of the outcome (Lee, 2000; Dörnyei, 2001). There a several ways that are followed during the pre-tasks.

(1) Supporting learners in performing a task similar to the task they will perform in the during-task phase of the lesson

(2) Asking students to observe a model of how to perform the task

\section{(3) Engaging learners in non-task activities designed to prepare them to perform the task}

\section{(4) Strategic planning of the main task performance}

Activities- ice-breakers, games, mini lessons, round robin sessions, table topic sessions, video and audio demonstrations, listening activities.

\section{b) During-tasks}

This is the main task itself where the students work in pairs or in small groups to complete the task. They are able to engage in discussion to fulfill the task requirements efficiently under time pressure (or not). The methodology of options available to the teacher through the during-task phrase has two main kinds. First, there are a couple of ways in which the task can be undertaken before the actual performance and thus, planned by the teacher. This is called 'Task-performance options'. Second, there are a number of 'Process options' that involve the teacher and student in on-line decision making about how to perform the task.

\section{1) 'Task-performance options}

- Concerns whether the students should be given a time limit to perform the tasks.

- Decide whether to allow students access the input data when they are performing.

- Introducing a surprise element into the tasks.

\section{2) Process Options}

- Students get together and prepare for the tasks

Activities- Dramas, Role-plays, Poster presentations, Debates, Prepared Speeches, Impromptu Speeches, Advertisements, Story-Completion, Brain-Storming Sessions and Discussions. 


\section{c) Post-tasks}

This is the phase where task performance can be seen. The teacher monitors the work and provides feedback when required. The report or act performed at the end of the task is the end result.

This has a number of options and there are three major pedagogical goals expected from a post-task.

1) To provide an opportunity for a repeat performance of the task

2) To encourage reflection on how the task was performed

3) To encourage attention to form (forms that proved problematic to the learners when they perform the task

By involving the students in "Reviewing learner errors, production Practice activities (PP), Consciousness raising tasks and Noticing activitie (Ellis, 2003) the learners can be assisted at this stage.

Activities - Voting Sessions, Q \& A, Feedback and Constructive Criticism

When creating lesson plans in the current research Blooms Taxonomy and CTBA were blended together in order to create motivation and confidence in the learners to communicate in English via a gradual mechanism.

\section{Methodology}

The methodology of the research is explained under 3 sub sections as follows.

\section{Sample Selection}

The sample was selected from 130 first year Engineering undergraduates who were freshly recruited to a Sri Lankan university. The population was subjected to an $\mathrm{OPI}^{2}$ (Oral Proficiency Interview). The performance was evaluated using an International English language Testing System (IELTS) rubric. The students who gained less than $40 \%$ from the rubric were selected as the purposive sample for enhancing confidence and motivation in their English speaking. 32 students were selected as the sample.

\section{Lesson plans and teaching process}

The teaching process incorporated in the study was mainly based on CTBA with the intention of enhancing speaker autonomy by enforcing confidence, motivation in students. It was also expected to reduce xenoglossophobia in the students. Therefore, the lesson plans on CTBAs were carefully developed as a separate syllabus based on the educational objectives of Blooms Taxonomy.

The teaching process was conducted for 15 weeks (academic semester) with each week having its original 3hour sessions on CTBAs. The lessons were set according to the six layered pyramid on 'knowledge-based skills'. The first 3 bottom layers of the pyramid contained 2 lessons each and gradually as the cognition of the students enhanced, they were exposed to more difficult tasks where speaker autonomy was prioritized. Therefore, the next 3 levels contained 3 lessons each targeting a specific objective.

Every CTBA contained pre, during and post-tasks. Pre-tasks were warmers used by the researcher to enhance motivation and boost the enthusiasm of the undergraduates to participate actively in the lessons. The warmers at

${ }^{2}$ An oral test containing three parts. At the initial stage, there will be a general discussion between the interviewer and the interviewee, which will be followed by a expression of opinion by the interviewee based on a topic related to Basic Interpersonal Communication Skills (BICS). The latter stage is an opinion sharing between the interviewer and the interviewee. 
times, contained mini-lessons and demonstrations. The during tasks were designed in order to improve the speaking skills in the students. These took most of the time. Initially, the students were made to work in collaboration in small groups and teams and later the number of the students was gradually lessoned paving way for more individual, autonomous presentations. The post-tasks were focused on providing opportunities to engage in presentations and enhancing speaker autonomy at the same time while offering peer and teacher feedback to the students. Attempts were taken to provide equal chances in communication to all students and to provide individual feedback based on their presentation. A main objective in the study was to find out the effective CTBA, which can be incorporated into the English classroom to enhance the speaking confidence and motivation levels of students. Therefore, it was important to provide priority to these specific communicative activities incorporated in the research. Thus, the CTBA appeared in diverse forms such as presentations, roleplays, interviews and debates. Hence, the lessons were conducted during a separate time slots provided by the faculty in order to avoid any disturbances to academic work of the students. The lessons were conducted by two lecturers in random terms to expose the students to different ways of giving and receiving commands, getting used to different accents and teaching methods. A friendly approach was maintained throughout the lessons. This was in order to develop confidence and motivation towards the English language on a daily basis. All lessons attempted to decrease classroom anxiety in students and therefore, the students were made to present the final version of their tasks in front of the classroom on a daily basis. At times, they were offered the opportunity of presenting their items in the main auditorium at the university. At the completion of the lessons, the students were expected to demonstrate traits of improved confidence and motivation in using the language, improved autonomous speaking ability, public speaking and leadership skills, time management etc.

Table 1: Blooms Taxonomy based CTBA

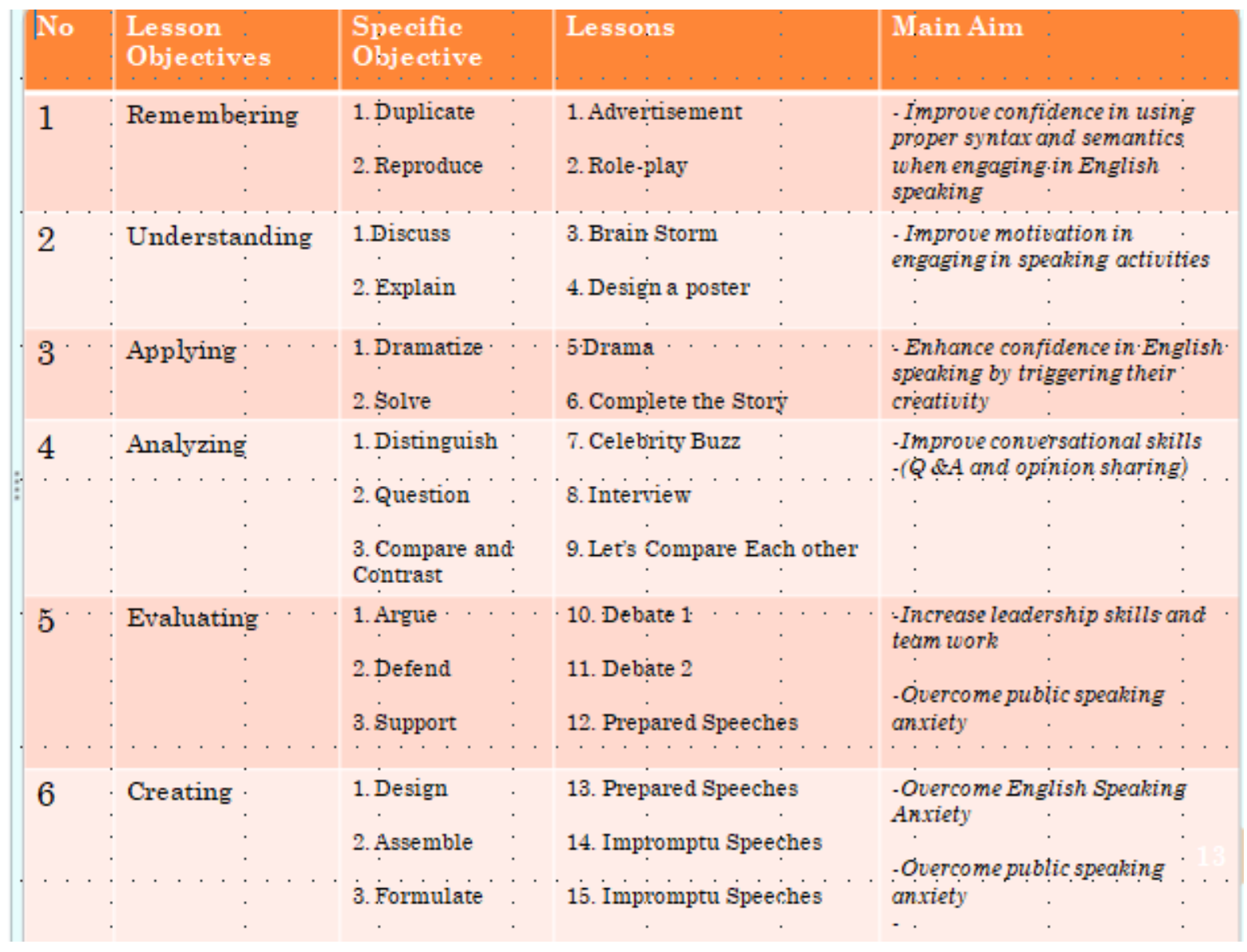




\section{Method}

The sample was subjected to the above lessons and were re-administered via a post-OPI where they were again evaluated on IELTS rubric marks. Apart from that, a random sample of 10 were interviewed in order to find out whether there was a difference between their motivation and confidence levels following the teaching-learning process.

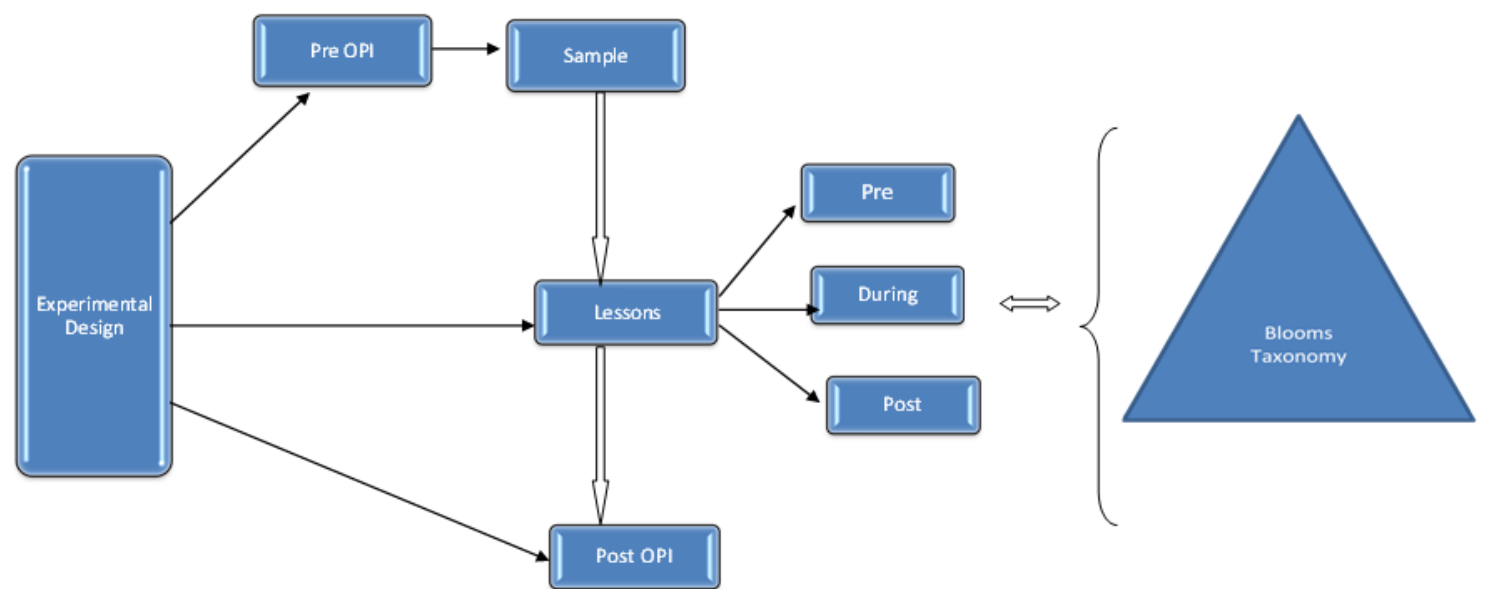

Figure 2 Experimental Design

\section{Analysis}

The analysis was a mixed approach where both qualitative and quantitative data were analyzed. Quantitative data gathered via the pre and post OPIs were analyzed using SPSS. The t-test was performed to identify the significant difference in the mean values of the tests and it was revealed that there was a significant difference between the test marks.

\begin{tabular}{|c|c|c|c|c|c|}
\hline \multicolumn{6}{|c|}{ Paired Samples Statistics } \\
\hline & & Mean & $\mathrm{N}$ & Std. Deviation & $\begin{array}{l}\text { Std. Error } \\
\text { Mean }\end{array}$ \\
\hline \multirow[t]{2}{*}{ Pair 1} & PosttestMarks & 67.88 & 32 & 9.033 & 1.597 \\
\hline & PretestMarks & 37.50 & 32 & 9.639 & 1.704 \\
\hline
\end{tabular}

Figure 3 Paired sample statistics.

The co-relation was .000 which was highly significant. 


\section{Paired Samples Correlations}

\begin{tabular}{|ll|r|r|r|}
\hline & \multicolumn{1}{|c|}{ N } & Correlation & Sig. \\
\hline Pair 1 & $\begin{array}{l}\text { PosttestMarks \& } \\
\text { PretestMarks }\end{array}$ & 32 & .673 & .000 \\
\hline
\end{tabular}

Figure 4 Paired sample correlations

\begin{tabular}{|c|c|c|c|c|c|c|c|c|c|}
\hline \multicolumn{10}{|c|}{ Paired Samples Test } \\
\hline & & \multicolumn{5}{|c|}{ Paired Differences } & \multirow[b]{3}{*}{$t$} & \multirow[b]{3}{*}{ df } & \multirow[b]{3}{*}{ Sig. (2-tailed) } \\
\hline & & \multirow[b]{2}{*}{ Mean } & \multirow[b]{2}{*}{ Std. Deviation } & \multirow{2}{*}{$\begin{array}{l}\text { Std. Error } \\
\text { Mean }\end{array}$} & \multicolumn{2}{|c|}{$\begin{array}{l}\text { 95\% Confidence Interval of the } \\
\text { Difference }\end{array}$} & & & \\
\hline & & & & & Lower & Upper & & & \\
\hline Pair 1 & $\begin{array}{l}\text { PosttestMarks - } \\
\text { PretestMarks }\end{array}$ & 30.375 & 7.568 & 1.338 & 27.646 & 33.104 & 22.704 & 31 & .000 \\
\hline
\end{tabular}

Figure 5 Paired sample tests

Qualitative data were analyzed based on the post interviews using the random sample. Observations were made throughout the research to witness the progression in the speaking autonomy of the students and were recorded on a journal maintained by the researcher throughout the progression of the research.

Table 2: Observations on the first and last day

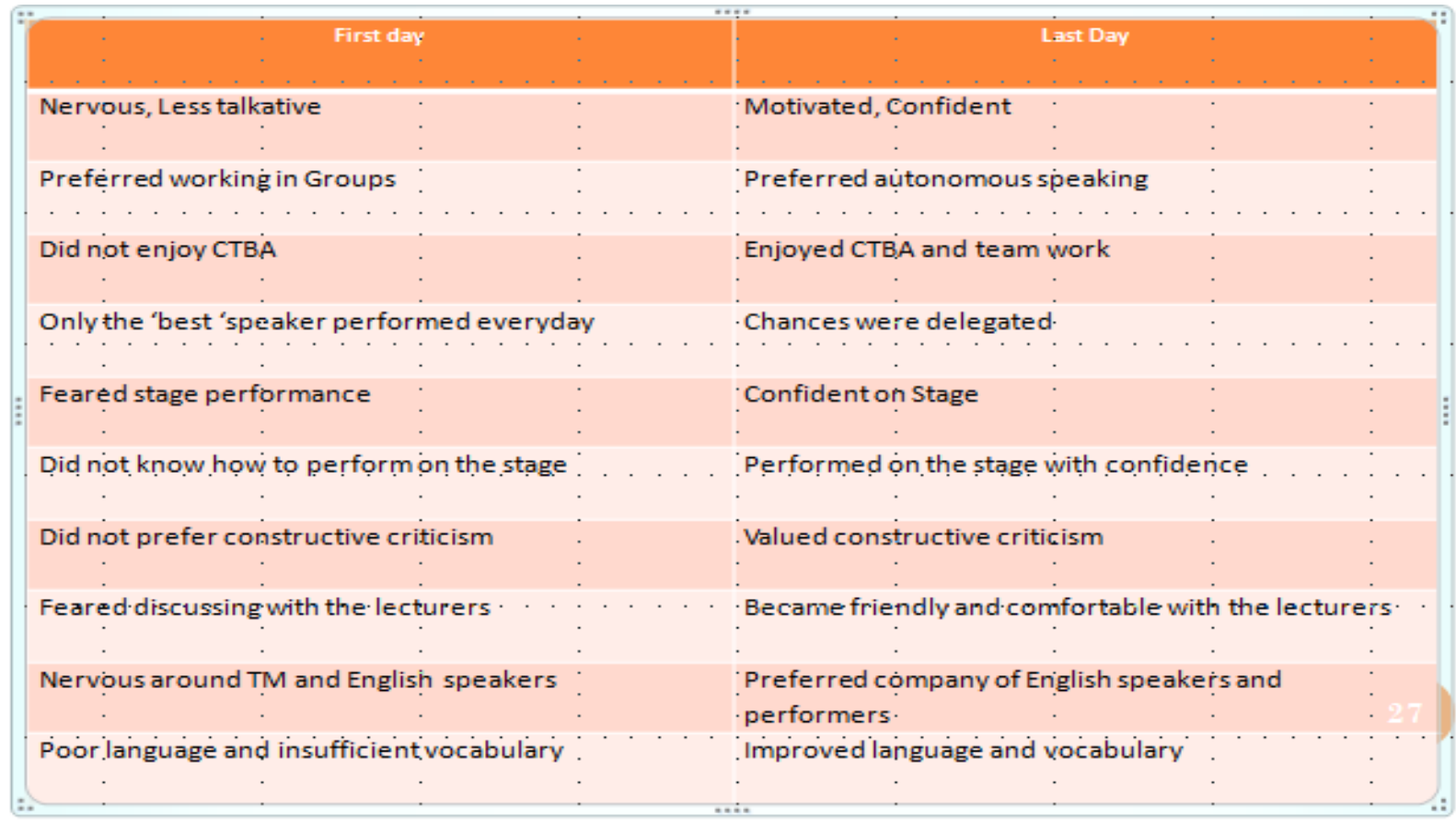

The interviews provided justification to this as $100 \%$ of the students declared that they improved confidence in performing and engaging in conversation in English language inside and outside the classroom. All students who were interviewed answered that they scaled themselves above 5 on a scale of 1-10 on confidence, following the 15 weeks. Observations indicated a difference in their English speaking ability and confidence at the completion of 15 weeks. It was also found out that the students preferred learning in collaboration and having 
pre tasks prior to the main task, gave sufficient exposure to the main lesson so that they can successfully complete it. Students revealed that assistance and demonstrations provided by the Toastmasters ${ }^{3}$ became immensely helpful when performing on the stage and that they could learn via observations. The feedback and constructive criticism of the well-known others, teacher and the peers was highly essential for them to improve and avoid future errors. The Q \& A sessions during post tasks assisted students to be prepared thoroughly and therefore, they had sufficient confidence to engage in discussion at the post-task phrase. It was revealed that getting 'votes' during post tasks boosted the motivation and confidence of the students as it helped them to identify the best speakers among themselves. $100 \%$ declared that the friendly classroom environment with approachable teachers and entertaining CTBA motivated them immensely and improved their confidence to speak in English language. They also stated that insufficient exposure to the language speaking and the examoriented nature inculcated to them during schools was a major reason for them to be reticent towards the language.

It was also found out that students do not have intrinsic motivation to learn a language as they were not taught the benefits of speaking and listening at school level. Since the local exams mainly focus on reading and writing, the students are not focused on developing the other skills related to language learning.

\section{Findings and Conclusion}

It was revealed that students gained significantly high marks at the post-test. The speaking ability, motivation towards the language and the confidence in expression had vastly improved at the post-OPI. All students who were interviewed, revealed that they had gained their confidence and motivation in speaking. As the students were made to perform in front of the classroom every week for a period of one academic term, their anxiety in engaging in public speaking was lessened. It was heightened as they were made to do it in a gradual process from groups of 6 to 5 to 2 to one. Therefore, it provided them the confidence to come forward and be familiar with the setting and the peers. Exposure to a gradual process of learning and speaking, result in autonomous speaking and performance. Therefore, the hypothesis that Blooms-Taxonomy coupled with CTBA develop speaker autonomy in the students.

A friendly, approachable teacher and energetic, lively tasks keeps the students highly motivated during language learning. The students preferred using technology and specially, listening to songs was appreciated as it was identified as a way to relive their stress during language learning. Using innovative TBAs which are entertaining as well. When students are made to bring out their creativity via diverse tasks such as role-plays, dramas, poster presentations etc, their motivation is triggered. This attitude and need has to be identified by the teacher prior to designing the lesson plans.

To improve public speaking, the students should be made to involve in oral presentations in front of the classrooms, initially, in front of the peers and gradually, outsiders. They should be provided opportunities to engage in presentations on stages and using microphones so that their public speaking anxiety can be lessened. More opportunities will result in lesser anxiety in speaking. Once their public speaking anxiety is reduced, they will have no problem communicating with peers and with outsiders during day-to-day activities.

Apart from this, the students should never be de-motivated during the teaching process. Their mistakes should be pointed out in a suttle manner and as constructive criticism. It should always be positively indicated and not in as mere negative feedback and criticism. This encourages the learner to learn from his/her mistakes rather than feeling embarrassed about it. This was one of the most effective strategies incorporated in the study during the post-task phrase.

\footnotetext{
${ }^{3}$ Public speakers
} 


\section{Suggestions}

A couple of suggestions and recommendations can be provided at the completion of the findings of the research. A comfortable environment and the friendly approach of the teacher, allows the students to be more interested and motivated in engaging in CTBA. Depending on the motivation, attitudes and skills of the students, the teacher should be able to provide the correct tasks and use the dogme ${ }^{4}$ method when necessary for them to better acquire a language. Student-centered CTBAs should be encouraged during English language teaching and learning and the teacher plays a considerably recognizable role here even though it is not the main one. Correct, relevant material, friendly environment and constructive criticism should be provided within the classroom for a better output of the students. If sufficient support is provided by the government to use technology for teaching, this method can be applied at school level so that the undergraduates will be correctly equipped with the right motivation when they enter university. This will result in a confident graduate output for the employment market in the future.

Gradual exposure to individual TBAs, reduces the nervousness of students as they get familiar with the environment. Students who are highly embarrassed at being laughed or who fear negative feedback should be provided opportunities to initially present activities in small groups. The number of members in groups should be eventually minimized by finally paving way for autonomous speaking. This will lessen their fear in public speaking as well as all CTBAs should be aimed at developing speaking skills. All tasks should provide students to engage in speaking and presentations in front of the classroom, on stages and using microphones and podiums when necessary. This will ease their anxiety in speaking and presentation phobia.

Following the three phrases of TBL (pre, during and post) assists the learners to grasp the skills effectively which will have positive result on the affective domain. The correct guidelines, tips on how to involve in speaking, introducing the new language and expressions and by exposing the students to demonstrations before the main task, enhances their cognition on presentation skills and performance at pre-task level. Sufficient time for practice during main tasks, with assistance provided by the teacher only when necessary and by exposing the students to engage in presentations in front of the classroom should be carried out in the during task phrase. Finally, during post task phrase, the correct feedback and individual comments boost the motivation of the students. Therefore, having easy to handle number of students in a classroom becomes a necessity. It will allow the teacher to provide individual feedback for the students. If this feedback mechanism can be carried out during school times, the students will be highly motivated in language learning as undergraduates.

The students' intrinsic motivation should be triggered at school level by emphasizing on the benefits which they can achieve by being able to competently speak in English language. Apart from that, before commencing a lesson, it is necessary to make students be aware about the objectives to be achieved from a lesson. If they are aware about the outcome of a lesson, their intrinsic motivation will pave the way for confidence to learn and communicate the language.

If the teachers are provided sufficient training on how to use TBAs during language learning and if students are made aware of the benefits of speaking English at school level itself, the anxiety levels will be much lesser at undergraduate levels. Apart from that, smaller numbers in classes will assist the teachers in providing individual feedback to students both at school and at undergraduate levels. Therefore, the schools and universities should be sufficiently funded to develop infrastructure. In addition, with sufficient funds, technology can be used for teaching which will also result in a better graduate output apt with the right skills and attitudes.

4 a communicative approach to language teaching that encourages teaching without published textbooks and focuses instead on conversational communication among learners and teacher 


\section{References}

Attanayake, A. U. (2018). Undergraduate ELT in Sri Lanka: Policy, Practice and Perspectives for South Asia. UK: Cambridge Scholars Publishing.

Armstrong, P. (2019). Bloom's Taxonomy. Vanderbilt University Center for Teaching. Retrieved from https://cft.vanderbilt.edu/guides-sub-pages/blooms-taxonomy/.

Balasuriya, L., \& Hughes, R. (2003, November). Education and employment: Sri Lanka at the crossroads. Paper submitted at the 9th International Conference on Sri Lanka Studies, Matara, Sri Lanka.

Bloom, B. S. (1956). Taxonomy of educational objectives (Vol. 1): Cognitive domain. New York: McKay, 2024.

Bolton, K. (2008). English in Asia, Asian Englishes, and the Issue of Proficiency. English Today (Vol.24, pp 312).

Eastbourne, L.T.C. (2017, December 8). Why the English Language is so Popular?. Retrieved from https://ltcenglish.com/why-english-language-is-so-popular/.

Dörnyei, Z. (2001). Motivation Strategies in the Language Classroom. United Kingdom: Cambridge University Press.

Ellis, R. (2009). Task-based Language Teaching: Sorting out the Misunderstandings. International journal of applied linguistics, 19(3), 221-246.

Ganta, T. G. (2015). The Strengths and Weaknesses of Task-based Learning (TBL) Approach. Scholarly research journal for interdisciplinary studies, 3(16), 2760-2771.

Gnanaseelan, J. (2001,February 24). Bilingual Sri Lankan Universities, a Necessity. The Daily Mirror. Retrieved from http://jgspring.blogspot.com/2012/10/bilingual-sri-lankan-universities.html.

Herscovitch, B. (2012, September 13). English is the Language of the Asian Century. Retrieved from http://www.abc.net.au/news/2012-09-13/herscovitch-english-asia/4257442.

Lee, L. (2000a). Blogging: Promoting Learner Autonomy and Intercultural Competence through Study Abroad. Language Learning \& Technology, 15(3), 87-109.

Perera, M. E. S. (2008). Coping with student heterogeneity in the English Language classrooms in Sri Lanka. National Education Commission. pp. 7.

Sanchez, A. (2004). The Task -Based Approach in Language Teaching. The International Journal of English Studies , 4(1), 39-71.

Willis, J. (1996). A Framework for Task-based Learning. Harlow, UK: Longman.

Willis, J. (1998), Task-based Learning: What kind of Adventure? The Language Teacher, 22(7), 17-18.

Wilson, L. O. (2016). Anderson and Krathwohl-Understanding the new version of Bloom's taxonomy. The second principle. The work of Leslie Owen Wilson. Ed. D. 